\title{
FBXW7 gene polymorphism is associated with type 2 diabetes in the Uygur population in Xinjiang, China
}

\author{
Shi-Qi Yan ${ }^{1,2 \dagger}$, Dilare Adi ${ }^{1,2 \dagger}$, Cheng Liu ${ }^{1,2}$, Meng-Meng Wang ${ }^{1,2}$, Jialin Abuzhalihana ${ }^{1,2}$, Yun Wu $\mathbf{u}^{1,2}$, \\ Zhen-Yan Fu ${ }^{1,2}$, Yi-Ning Yang ${ }^{1,2}$, Xiao-Mei Li ${ }^{1,2}$, Xiang Xie ${ }^{1,2}$, Fen Liư ${ }^{2}$, Bang-Dang Chen ${ }^{2}$ and Yi-Tong Ma ${ }^{1,2^{*}}$ (D)
}

\begin{abstract}
Background: FBXW7 gene expression is positively correlated with glycolipid metabolism and is associated with diabetes in animal models. In the current study, we focused on exploring whether genetic variants of the FBXW7 gene were associated with type 2 diabetes (T2DM) and the risk factors for T2DM in Uygur people in Xinjiang, China.

Methods: A total of 2164 Chinese Uygur subjects (673 T2DM patients and 1491 controls) were recruited for our casecontrol study, and four SNPs (rs10033601, rs2255137, rs2292743 and rs35311955) of the FBXW7 gene were genotyped using the improved multiplex ligation detection reaction (iMLDR) technique.

Results: Our study showed that the genotypes using the overdominant model (GA vs AA+ GG) of rs10033601 and using the overdominant model (TA vs TT + AA) of rs2292743 were significantly different between T2DM patients and the controls $(P=0.005$ and $P=0.012$, respectively). After multivariate adjustments for confounders, the rs 10033601 and rs2292743 SNPs were still independent risk factors for T2DM [GA vs AA + GG: odds ratio $=1.35,95 \%$ confidence interval $(C l)=1.12-1.64, P=0.002 ; \mathrm{TA}$ vs TT $+\mathrm{AA}: \mathrm{OR}=1.28,95 \% \mathrm{Cl}=1.06-1.55, P=0.011]$. Participants within the Chinese Uygur populations and who with the GA genotype of rs 10033601 and the TA genotype of rs2292743 were associated with significantly elevated glucose levels.
\end{abstract}

Conclusions: Our study revealed that both rs 10033601 and rs2292743 of the FBXW7 gene were associated with T2DM in the Uygur populations in Xinjiang.

Keywords: FBXW7, Polymorphism, Type 2 diabetes

\section{Introduction}

Type 2 diabetes mellitus (T2DM), which is the most common and dominant type of diabetes and accounts for approximately $90 \%$ of all cases, is a multifactorial disorder with an increasing incidence [1]. A large number of risk factors are associated with T2DM, including lifestyle changes, environmental factors and genetic

\footnotetext{
${ }^{*}$ Correspondence: myt_xj@sina.com

${ }^{\dagger}$ Shi-Qi Yan and Dilare Adi contributed equally to this work.

1 Department of Cardiology, First Affiliated Hospital of Xinjiang Medical University, Urumai 830054, P.R. China

Full list of author information is available at the end of the article
}

components [2-5]. T2DM is the most common endocrine and metabolic disease, is caused by a combination of environmental and genetic factors and is also a recognized independent risk factor for cardiovascular disease (CAD) [6]. Persistently high blood glucose levels can lead to micro- and macrovascular damage, which further leads to CAD [7]. In recent decades, studies have demonstrated the polygenic aspect of T2DM and have revealed the effects of numerous gene variants on the susceptibility of the disease [8-11].

F-box and WD repeat domain-containing 7 (FBXW7) is an E3-ubiquitin ligase that mediates the recognition original author(s) and the source, provide a link to the Creative Commons licence, and indicate if changes were made. The images or other third party material in this article are included in the article's Creative Commons licence, unless indicated otherwise in a credit line to the material. If material is not included in the article's Creative Commons licence and your intended use is not permitted by statutory regulation or exceeds the permitted use, you will need to obtain permission directly from the copyright holder. To view a copy of this licence, visit http://creativecommons.org/licenses/by/4.0/. The Creative Commons Public Domain Dedication waiver (http://creativeco mmons.org/publicdomain/zero/1.0/) applies to the data made available in this article, unless otherwise stated in a credit line to the data. 
of phosphorylated substrates, such as SREBPs, for proteolysis [12, 13]. FBXW7 interacts with nuclear SREBP family genes and improves their ubiquitination, eventually resulting in their degradation, suggesting that FBXW7 could regulate blood lipids [12-16]. Several studies have demonstrated that disorders of lipid metabolism are involved in the pathogenesis of CAD $[17,18]$. Our preliminary findings suggested that the FBXW7 gene variant is associated with CAD in the Uygur Chinese population. Interestingly, Fbxw7 has also been noted to play a vital role in glucose homeostasis by promoting the ubiquitination and degradation of Fetuin-A in a manner dependent on the phosphorylation of Serine 305 and Serine 309. Liver-specific ablation of FBXW7 disrupts glucose homeostasis. However, in the obese liver, FBXW7 expression confers several beneficial metabolic effects, such as protection against glucose intolerance, insulin resistance, and hyperglycaemia [19]. Additionally, despite the widespread reports of Fbxw7 involvement in glucose metabolism, its single nucleotide polymorphisms (SNPs) have not been studied. Hence, the aim and focus of the present research was to assess the associations between genetic polymorphisms of FBXW7 and T2DM in the Uygur Chinese populations in Xinjiang, China.

\section{Methods}

\section{Ethical approval of the study protocol}

The Ethics Committee of the First Affiliated Hospital of Xinjiang Medical University approved this study (Ethical approval number: K202011-06), and it was executed in accordance with the standards of the Declaration of Helsinki. Each participant gave written informed consent and explicit permission for pertinent clinical data collection and DNA analyses.

\section{Subjects}

A total of 2164 Uygur participants were recruited randomly (1483 men, 681 women) from the Medical University Hospital between August 2013 and November 2016. These subjects, who all resided in the Xinjiang Uygur Autonomous Region of China, passed the eligibility criteria and had genotyping data of the FBXW7 gene. A total of 672 patients that were diagnosed with T2DM were assigned to the case group. T2DM was defined as those who had a fasting plasma glucose (FPG) $\geq 7.0 \mathrm{mmol} / \mathrm{l}$, a $2 \mathrm{~h}$ postload plasma glucose $(2 \mathrm{hPG}) \geq 11.1 \mathrm{mmol} / \mathrm{l}$, or a history of having hypoglycaemia therapy [20]. A total of 1492 subjects with normal glucose tolerance (NGT) were designated as the control group. NGT was defined as FPG $<6.1 \mathrm{mmol} / \mathrm{l}$ and $2 \mathrm{hPG}<7.8 \mathrm{mmol} / \mathrm{l}$.

\section{Genotyping}

Four tag SNPs of FBXW7 were obtained using Haploview 4.2 software alongside the International HapMap project website phases I and II (http://www.hapmap. org). rs10033601 (SNP1), rs2255137 (SNP2), rs2292743 (SNP3), and rs35311955 (SNP4) were included by using the minor allele frequency (MAF) $\geq 0.05$ and the linkage disequilibrium patterns with $r^{2} \geq 0.8$ as the cut-off. We perform the linkage disequilibrium blocks in the genome area in FBXW7 genes by using the Ldheatmap software in $\mathrm{R}$ package. As shown in Fig. 1 , the $\mathrm{LD}$ values are displayed as follows: the higher the $R^{2}$ value, the deeper the redness of the color. A standard venipuncture technique was used to obtain blood samples from the participants using EDTA-containing tubes. Using a blood genome extraction kit, we extracted the DNA from the blood leukocytes at the periphery (Beijing Bioteke Corporation, Beijing, China). Without knowledge of the subject's data, genotyping was performed, and approximately $10 \%$ of the samples were duplicated for the purposes of monitoring the quality of the genotyping.

\section{Statistical analysis}

SPSS version 23.0 for Windows was used to perform the statistical analyses of the study (SPSS Inc. Chicago, IL, USA). The chi-square test was used to assess the

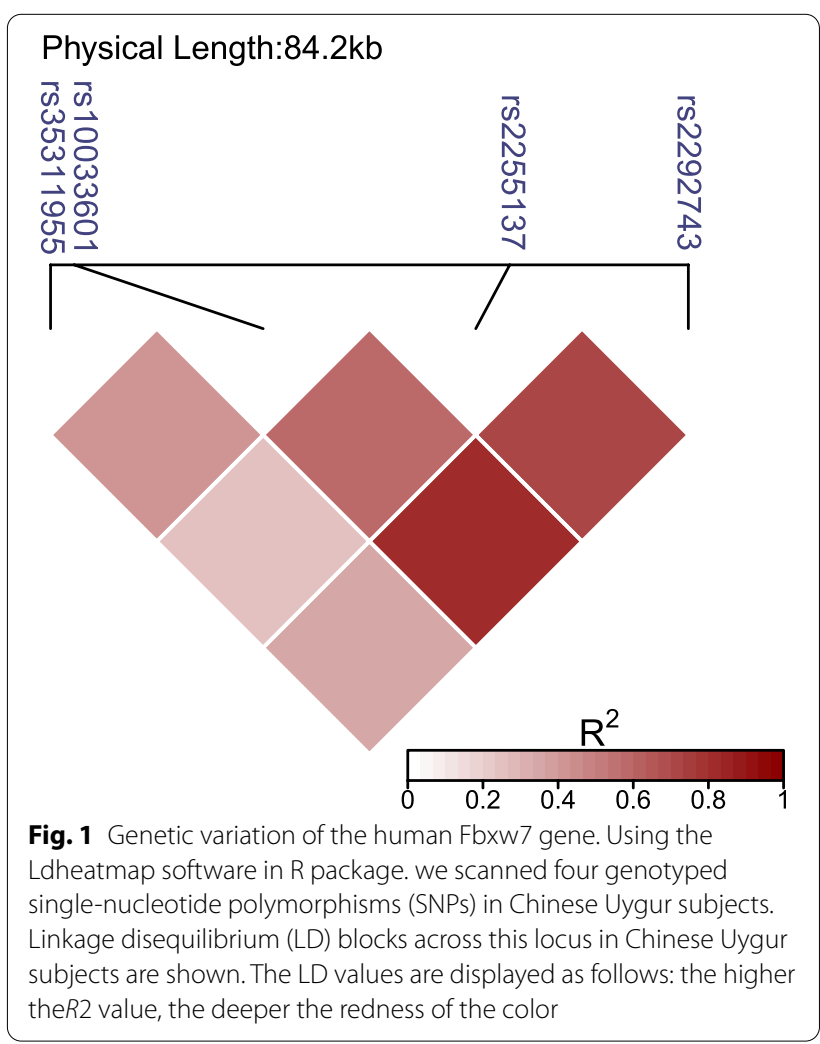


equilibrium assessed by the Hardy-Weinberg test. The Kolmogorov-Smirnov test was used to examine the normality of the variables. Data were reported as the mean plus or minus the S.D. for normally distributed variables. However, the difference between the male and female patients was assessed with the two-independent-sample T-test. The chi-square test was used to analyse the categorical data, such as the differences of the frequencies of drinking, genotypes, smoking and hypertension between the groups. General linear analysis was performed to test the existing association between the lipid profiles and the FBXW7 genotypes, and logistic regression analyses were used to assess the contribution of the major risk factors. Two-tailed $P$-values of 0.05 were considered significant.

\section{Results}

\section{Clinical characteristics of subjects}

The subjects' baseline characteristics are shown in Table 1. There were significant differences in serum total cholesterol (TC), triglycerides (TGs), low-density lipoprotein cholesterol (LDL-C), high-density lipoprotein cholesterol (HDL-C), fasting blood glucose (FBG), body mass index (BMI), blood urea nitrogen (Bun), uric acid levels and prevalence of hypertension between the two groups (all $P<0.05)$.

Table 1 Clinical and metabolic characteristics of subjects

\begin{tabular}{lllrr}
\hline Characteristics & $\begin{array}{l}\text { Control } \\
(\boldsymbol{n}=\mathbf{1 4 9 1})\end{array}$ & DM $(\boldsymbol{n = 6 7 3 )}$ & X2 or t & P value \\
\hline Age (years) & $56.9 \pm 11.8$ & $57.8 \pm 11.9$ & 2.013 & 0.052 \\
$\begin{array}{l}\text { Gender, female } \\
\text { (\%) }\end{array}$ & $465(31.2 \%)$ & $216(32.1 \%)$ & 0.177 & 0.689 \\
Smoking, n(\%) & $787(52.8 \%)$ & $377(56 \%)$ & 1.952 & 0.177 \\
Drinking, n (\%) & $473(31.7 \%)$ & $217(31.2 \%)$ & 0.058 & 0.842 \\
Hypertension, & $714(47.6 \%)$ & $448(66.6 \%)$ & 65.079 & $<\mathbf{0 . 0 0 1}$ \\
n (\%) & & & & \\
BMI, mean (SD) & $25.84 \pm 3.41$ & $26.17 \pm 3.39$ & 2.058 & $\mathbf{0 . 0 4 0}$ \\
Cr, mean (SD) & $73.80 \pm 18.03$ & $73.43 \pm 20.27$ & 0.425 & 0.671 \\
BUN, mean (SD) & $5.38 \pm 1.46$ & $5.56 \pm 2.05$ & 2.356 & $\mathbf{0 . 0 1 9}$ \\
Uric acid, mean & $318.65 \pm 81.47$ & $302.41 \pm 81.90$ & 4.284 & $<\mathbf{0 . 0 0 1}$ \\
$\quad$ (SD) & & & & \\
FBG, mean (SD) & $5.18 \pm 1.29$ & $8.08 \pm 3.66$ & 27.060 & $<\mathbf{0 . 0 0 1}$ \\
TG, mean (SD) & $1.79 \pm 1.11$ & $2.00 \pm 1.29$ & 3.918 & $<\mathbf{0 . 0 0 1}$ \\
TC, mean (SD) & $4.11 \pm 1.22$ & $3.98 \pm 1.27$ & 2.206 & $\mathbf{0 . 0 2 8}$ \\
HDL-C, mean (SD) & $1.06 \pm 0.33$ & $0.98 \pm 0.31$ & 4.985 & $<\mathbf{0 . 0 0 1}$ \\
LDL-C, mean (SD) & $2.55 \pm 0.86$ & $2.41 \pm 0.97$ & 3.465 & $<\mathbf{0 . 0 0 1}$ \\
\hline
\end{tabular}

Data are presented as number of patients (\%) or mean standard \pm deviation $B M I$ Body mass index, $C r$ Creatinine, BUN Blood urea nitrogen, FBG Fasting blood glucose, TG Triglyceride, TC Total cholesterol, HDL-C High density lipoproteincholesterol, $L D L-C$ Low-density lipopretein-cholesterol

\section{Distribution of SNPs of FXBW7 gene in subjects}

The distributions of the SNPs in the FXBW7 gene are shown in Table 2. The genotype distributions of the four SNPs were in accordance with the Hardy-Weinberg equilibrium balance (all $P>0.05$ ). Our results indicated that the distributions of rs2255137 and rs35311955 SNPs between the case and control groups were similar (all $P>0.05$ ). For rs10033601 and rs2292743, the distribution of genotypes and the overdominant model\{(GA vs $\mathrm{AA}+\mathrm{GG}),(\mathrm{TA}$ vs TT + AA) showed a significant difference between the two groups $(P=0.005, P=0.012)$.

Multivariable logistic regression analyses revealed that after adjusting for the major confounding factors, including BMI, BUN, TG, uric acid, Cr, LDL-C, age, TC, sex, HDL-C, smoking, and hypertension, the rs10033601 SNP was an independent risk factor for T2DM [GA vs $\mathrm{AA}+\mathrm{GG}$ : odds ratio $(\mathrm{OR})=1.35,95 \%$ confidence interval $(\mathrm{CI})=1.12-1.64, P=0.002$, Table 3]. However, after adjusting for confounders, rs2292743 was still an independent risk factor for T2DM [TA vs TT+ AA: $\mathrm{OR}=1.28,95 \% \mathrm{CI}=1.06-1.55, P=0.011$, Table 4].

\section{Univariate logistic regression analysis of rs 10033601 and rs2292743 genotypes for T2DM risk factors}

The relationship between FXBW7 gene polymorphisms and recognized risk factors for T2DM as following in Tables 5 and 6. The rs2292743 SNPs were shown to significantly increase T2DM risk in obese people with $\mathrm{BMI} \geq 28 \mathrm{~kg} / \mathrm{m}^{2}$ (TA vs $\mathrm{TT}+\mathrm{AA}: \mathrm{OR}=1.37,95 \%$ $\mathrm{CI}=1.13-1.67, P=0.002)$.

\section{Discussion}

In the present study, we found that rs10033601 and rs2292743 variations in the FBXW7 gene were all strongly correlated with the T2DM susceptibility in the Uygur Chinese population. Thus far, this was the first study to investigate the common allelic variants in the FBXW7 gene and their association with T2DM in the Uygur Chinese population.

Previous investigations have revealed the associations of the FBXW7 gene with tumour suppression and the progression of the cell cycle [21-23]. Moreover, FBXW7 has an essential role in regulating the metabolism of energy and lipids. FBXW7 regulates the functions of the SREBO protein family that control the synthesis of triglycerides and their stability. SREBP family gene stabilization enhances cholesterol and fatty acid synthesis and induces the expression of SREBP alongside the uptake of LDL-C [24]. In addition, Bengoechea et al. [25] found that FBXW7 negatively regulates adipocyte differentiation through targeted intervention in C/EBP $\alpha$ for degradation. FBXW7 plays key roles in regulating lipogenesis 
Table 2 Distribution of SNPs of FXBW7 gene in the cases and controls

\begin{tabular}{|c|c|c|c|c|c|}
\hline Genotype & Model & & Case $(\mathrm{n}, \%)$ & $\begin{array}{l}\text { Control (n, } \\
\%)\end{array}$ & $P$ value \\
\hline \multirow[t]{11}{*}{ rs10033601 } & \multirow{3}{*}{$\begin{array}{l}\text { Codomi- } \\
\text { nant }\end{array}$} & $A A$ & $254(37.7)$ & $512(34.3)$ & \multirow[t]{3}{*}{0.018} \\
\hline & & GA & $281(41.8)$ & $719(48.2)$ & \\
\hline & & GG & $138(20.5)$ & $260(17.4)$ & \\
\hline & \multirow[t]{2}{*}{ Dominant } & AA & $254(37.7)$ & $512(34.3)$ & \multirow[t]{2}{*}{0.132} \\
\hline & & $\mathrm{GA}+\mathrm{GG}$ & $419(62.3)$ & $979(65.7)$ & \\
\hline & \multirow[t]{2}{*}{ Recessive } & $\mathrm{AA}+\mathrm{GA}$ & $535(79.5)$ & 1231 (82.6) & \multirow[t]{2}{*}{0.093} \\
\hline & & GG & $138(20.5)$ & $260(17.4)$ & \\
\hline & \multirow{2}{*}{$\begin{array}{l}\text { Overdomi- } \\
\text { nant }\end{array}$} & $\mathrm{AA}+\mathrm{GG}$ & $392(58.2)$ & $772(51.8)$ & \multirow[t]{2}{*}{0.005} \\
\hline & & $\mathrm{GA}$ & $281(41.8)$ & 719 (48.2) & \\
\hline & \multirow[t]{2}{*}{ Allele } & A & 789 (58.6) & $1743(58.5)$ & \multirow[t]{2}{*}{0.918} \\
\hline & & G & $557(41.4)$ & 1239 (41.5) & \\
\hline \multirow[t]{11}{*}{ rs2255137 } & \multirow{3}{*}{$\begin{array}{l}\text { Codomi- } \\
\text { nant }\end{array}$} & $\mathrm{TT}$ & 199 (29.6) & $426(28.6)$ & \multirow[t]{3}{*}{0.471} \\
\hline & & $C T$ & $311(46.2)$ & $730(49.0)$ & \\
\hline & & CC & $163(24.2)$ & $335(22.5)$ & \\
\hline & \multirow[t]{2}{*}{ Dominant } & $\mathrm{TT}$ & $199(29.6)$ & 426 (28.6) & \multirow[t]{2}{*}{0.335} \\
\hline & & $\mathrm{CT}+\mathrm{CC}$ & $474(70.4)$ & 1065 (71.4) & \\
\hline & \multirow[t]{2}{*}{ Recessive } & $\mathrm{TT}+\mathrm{CT}$ & $510(75.8)$ & $1156(77.5)$ & \multirow[t]{2}{*}{0.37} \\
\hline & & CC & $163(24.2)$ & 335 (22.5) & \\
\hline & \multirow{2}{*}{$\begin{array}{l}\text { Overdomi- } \\
\text { nant }\end{array}$} & $\mathrm{TT}+\mathrm{CC}$ & $362(53.8)$ & $761(51.0)$ & \multirow[t]{2}{*}{0.236} \\
\hline & & $\mathrm{CT}$ & $311(46.2)$ & $730(49.0)$ & \\
\hline & \multirow[t]{2}{*}{ Allele } & $T$ & 709 (52.7) & $1582(53.1)$ & \multirow[t]{2}{*}{0.818} \\
\hline & & C & $637(42.3)$ & $1400(46.9)$ & \\
\hline \multirow[t]{11}{*}{ rs2292743 } & \multirow{3}{*}{$\begin{array}{l}\text { Codomi- } \\
\text { nant }\end{array}$} & TT & $158(23.5)$ & $318(21.3)$ & 0.039 \\
\hline & & TA & $288(42.3)$ & 726 (48.7) & \\
\hline & & AA & 227 (33.7) & 447 (30.0) & \\
\hline & Dominant & $\mathrm{TT}$ & $158(23.5)$ & $318(21.3)$ & 0.263 \\
\hline & & $\mathrm{TA}+\mathrm{AA}$ & $515(76.5)$ & 1173 (78.7) & \\
\hline & Recessive & $\mathrm{TT}+\mathrm{TA}$ & 446 (66.3) & $1044(70.0)$ & 0.088 \\
\hline & & $\mathrm{AA}$ & $227(33.7)$ & $447(30.0)$ & \\
\hline & Overdomi- & $\mathrm{TT}+\mathrm{AA}$ & 385 (57.2) & 765 (51.3) & 0.012 \\
\hline & & TA & $288(42.8)$ & 726 (48.7) & \\
\hline & Allele & $\mathrm{T}$ & $604(44.9)$ & $1362(45.7)$ & 0.624 \\
\hline & & A & $742(55.1)$ & $1620(54.3)$ & \\
\hline rs35311955 & Codomi- & GG & $400(59.4)$ & 886 (59.4) & 0.607 \\
\hline & 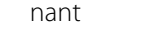 & GC & $230(34.2)$ & $525(35.2)$ & \\
\hline & & CC & $43(6.4)$ & $80(5.4)$ & \\
\hline & Dominant & GG & $400(59.4)$ & 886 (59.4) & 1.000 \\
\hline & & $\mathrm{GC}+\mathrm{CC}$ & $273(40.6)$ & 606 (40.6) & \\
\hline & Recessive & $\mathrm{GG}+\mathrm{GC}$ & $630(93.6)$ & 1411 (94.6) & 0.367 \\
\hline & & CC & $43(6.4)$ & $80(5.4)$ & \\
\hline & Overdomi- & $\mathrm{GG}+\mathrm{CC}$ & $360(53.7)$ & $758(51.0)$ & 0.712 \\
\hline & & GC & $230(34.2)$ & $728(49.0)$ & \\
\hline & Allele & G & $1030(76.5)$ & $2297(77.0)$ & 0.715 \\
\hline & & & $316(23.5)$ & $685(23.0)$ & \\
\hline
\end{tabular}

Table 3 Results of logistic analysis (rs10033601)

\begin{tabular}{llll}
\hline & OR & 95\%Cl & P value \\
\hline $\begin{array}{llll}\text { rs10033601(GA } \\
\text { Vs.AA+GG) }\end{array}$ & 1.354 & $1.118-1.640$ & $\mathbf{0 . 0 0 2}$ \\
Gender & 1.142 & $0.872-1.495$ & 0.333 \\
Age & 1.012 & $1.001-1.024$ & 0.032 \\
BMl & 1.024 & $0.995-1.053$ & 0.110 \\
Hypertension & 2.059 & $1.689-2.510$ & $\mathbf{0 . 0 0 0}$ \\
Smoking & 1.242 & $0.972-1.588$ & $\mathbf{0 . 0 8 4}$ \\
Drinking & 1.009 & $0.791-1.286$ & 0.943 \\
BUN & 1.091 & $1.027-1.158$ & 0.005 \\
Cr & 1.001 & $0.995-1.007$ & 0.720 \\
Uric acid & 0.996 & $0.995-0.997$ & 0.000 \\
TG & 1.181 & $1.084-1.286$ & 0.000 \\
TC & 0.934 & $0.832-1.049$ & 0.250 \\
HDL-C & 0.507 & $0.364-0.706$ & 0.000 \\
LDL-C & 0.909 & $0.776-1.064$ & 0.234 \\
\hline
\end{tabular}

Table 4 Results of logistic analysis (rs2292743)

\begin{tabular}{llll}
\hline & OR & $\mathbf{9 5 \% C l}$ & P value \\
\hline rs2292743(TA vs.TT+AA) & 1.280 & $1.058-1.550$ & $\mathbf{0 . 0 1 1}$ \\
Gender & 1.143 & $0.873-1.496$ & 0.331 \\
Age & 1.012 & $1.001-1.023$ & $\mathbf{0 . 0 3 7}$ \\
BMI & 1.023 & $0.995-1.053$ & 0.113 \\
Hypertension & 2.045 & $1.078-2.493$ & $\mathbf{0 . 0 0 0}$ \\
Smoking & 1.248 & $0.997-1.595$ & 0.076 \\
Drinking & 1.000 & $0.785-1.274$ & 0.999 \\
BUN & 1.092 & $1.028-1.160$ & $\mathbf{0 . 0 0 4}$ \\
Cr & 1.001 & $0.995-1.007$ & 0.713 \\
Uric acid & 0.996 & $0.995-0.997$ & $\mathbf{0 . 0 0 0}$ \\
TG & 1.183 & $1.086-1.288$ & $\mathbf{0 . 0 0 0}$ \\
TC & 0.935 & $0.832-1.050$ & 0.254 \\
HDL-C & 0.511 & $0.367-0.712$ & $\mathbf{0 . 0 0 0}$ \\
LDL-C & 0.912 & $0.779-1.068$ & 0.253 \\
\hline
\end{tabular}

and cell proliferation and differentiation in the liver, and this has been shown both in basic biological and clinical experiments.

Alteration of lipid metabolism is a risk factor and characteristic feature of atherosclerosis. Atherosclerosis develops as a result of a multistep process ultimately leading to cardiovascular disease associated with a high morbidity and a high mortality. As previously mentioned, T2DM is a metabolic disorder characterized by chronic hyperglycaemia. Changes in blood lipid levels in diabetic patients are associated with an increased production of triglyceride-rich lipoproteins in the liver, leading to an increased formation of atherosclerotic very low-density 
Table 5 Univariate logistic regression analysis of rs10033601 genotypes for T2DM risk factors

\begin{tabular}{lllll}
\hline rs10033601 & AA + GG $(\boldsymbol{n}=\mathbf{1 1 6 4})$ & GA $(\boldsymbol{n}=\mathbf{1 0 0 0})$ & OR & $\mathbf{9 5 \% C l}$ \\
\hline $\mathrm{BMl} \geq 28 \mathrm{~kg} / \mathrm{m} 2$ & $319(26.9 \%)$ & $237(23.7 \%)$ & 1.184 & $0.974-1.439$ \\
$\mathrm{Age} \geq 48$ & $1001(86.0 \%)$ & $841(84.1 \%)$ & 1.161 & $0.916-1.471$ \\
\hline
\end{tabular}

Table 6 Univariate logistic regression analysis of rs2292743 genotypes for T2DM risk factors

\begin{tabular}{lllll}
\hline rs2292743 & TT + AA $(\boldsymbol{n}=\mathbf{8 0 3})$ & TA $(\boldsymbol{n}=\mathbf{1 0 1 4})$ & OR & 95\%Cl \\
\hline $\mathrm{BMl} \geq 28 \mathrm{~kg} / \mathrm{m} 2$ & $324(28.2 \%)$ & $226(22.3 \%)$ & 1.368 & $1.124-1.664$ \\
Age $\geq 48$ & $995(86.5 \%)$ & $847(83.5 \%)$ & 1.266 & $0.999-1.604$ \\
\hline
\end{tabular}

lipoproteins (VLDL) [26]. This can eventually accelerate the development of atherosclerosis and even lead to CAD.

The relationship between T2DM and Fbxw7 was first studied by Zhao et al. [27]; they investigated the liver triglyceride contents as well as the expression levels of proinflammatory cytokines in WAT of FBXW7 LKO mice and found that they were markedly increased. Additionally, this study knocked down fetuin-A expression in FBXW7 LKO mice and observed that FBXW7 improves glucose metabolism by promoting fetuin-A degradation. A corresponding decrease in fetuin-A levels was also observed in FBXW7-overexpressing obese mice compared to WT controls. These findings showed that FBXW7 contributed to the elevated glucose levels.

In the present study, we genotyped polymorphisms of rs10033601, rs2255137, rs2292743 and rs35311955 of SNPs in the FBXW7 gene and found that rs 10033601 and rs2292743 were associated with T2DM. The rs10033601 GA genotype and the rs2292743 TA genotype had higher frequencies in T2DM patients than in controls. After adjusting for several confounders, this association remained, indicating that rs $10033601 \mathrm{GA}$ and rs2292743 TA were independent risk factors for T2DM. According to the definition of genetics, the over-dominant model means the condition of a heterozygote having a phenotype that is more pronounced or better adapted than that of either homozygote. This may be due to the accumulation of different alleles. So heterozygotes for rs 10033601 and rs2292743 were risk factors for the development of T2DM. Together, these results might provide convincing evidence assuming that genetic polymorphisms of the FBXW7 gene are associated with T2DM. However, the mechanisms that may link the FBXW7 genetic polymorphisms to T2DM remain unclear.

There are a number of limitations that might have influenced some of the study's findings. First, this study was only carried out in the First Affiliated Hospital of the
Xinjiang Medical University. Conclusions of the study were primarily drawn using the observed associations, and we failed to obtain a cause-and-effect relationship between the risk factors and T2DM. Second, the Uygur Chinese population is an admixed population that mainly lives in the Xinjiang Uygur Autonomous Region of China, and there is a lack of individual genetic background information. Third, the present study lacked a functional validation. Additional studies need to be undertaken to clarify the underlying molecular mechanisms that underlie the associations of the FBXW7 gene polymorphisms with T2DM. Four, The current research is only limited to the Uygur population, and the future work should try to supplement the research of Han and other ethnic groups as the control group.

\section{Conclusions}

In conclusion, our study revealed that rs10033601 and rs2292743 of the FBXW7 gene were associated with T2DM in Uygur subjects in Xinjiang. Those who had the GA genotype of rs10033601 as well as those subjects who had the TA genotype of rs 2292743 were found to have an association with the presence of T2DM.

\section{Acknowledgements \\ Our gratitude and thanks goes to all the patients who accepted and took part in this study.}

\section{Authors' contributions}

The experiments were designed and conceived by DA and SY who also wrote the draft of the experiment's manuscript: data collections as well as analyses inclined to the statistics were done by FL, JA and BC; the laboratory experiments were conducted by DA, MMW and $C L$ while the critical comments that were pertained to the draft were given by $X \mathrm{~L}, \mathrm{YY}, \mathrm{XX}$ and $\mathrm{YM}$ who also took part in the writing of the manuscript. This study was under supervision and had its clinical assessments review done by DA, SY as well as YW. The final approval of the whole study was given by all the authors who had gone through whole of the study.

\section{Funding}

This work was supported financially by the Open project of Key Laboratory (No. 2020D04008) from Science and Technology Department of Xinjiang Uygur Autonomous Region. The National Natural Science Foundation of 
China (No. 81873490, 91957208), The State Key Laboratory of Pathogenesis, Prevention and Treatment of High Incidence Diseases in Central Asia Xinjiang Medical University (No. SKL-HIDCA-2021-XXG2).

\section{Availability of and data materials}

There will be no sharing of the obtained data since it will be required in another study.

\section{Declarations}

\section{Ethics approval and consent to participate}

The hospital of Xinjiang medical University had their board (Ethical Review board of the institution first affiliate university) approve this study that also had the patients enroll the written informed consent.

\section{Consent for publication}

Not applicable.

\section{Competing interests}

A declaration was made by the authors that this study has no competing interests.

\section{Author details}

'Department of Cardiology, First Affiliated Hospital of Xinjiang Medical University, Urumqi 830054, P.R. China. ${ }^{2}$ Xinjiang Key Laboratory of Cardiovascular Disease Research, Urumqi 830054, P.R. China.

Received: 8 March 2021 Accepted: 19 July 2021

Published online: 09 August 2021

\section{References}

1. Cao Y, Li X, Lu C, et al. The relationship between vitronectin and hepatic insulin resistance in type 2 diabetes mellitus. Endocr J. 2018;65:747-53.

2. Zhang P, Li T, Wu X, et al. Oxidative stress and diabetes: antioxidative strategies. Front Med. 2020;14(5):5837-600.

3. Hussain MK, Deli FA, Algenabi AH, et al. Adiponectin gene polymorphisms as a predictor for development of type 2 diabetes mellitus in Iraqi population. Gene. 2018;662:118-22.

4. Cai XL, Ji LN. Treatment response between Asian and non-Asian patients with type 2 diabetes: is there any similarity or difference? Chin Med J. 2019;132:1-3.

5. Dou HY, Wang YY, Yang N, et al. Association between genetic variants and characteristic symptoms of type 2 diabetes: a matched case-control study. Chin J Integr Med. 2017;23:415-24.

6. Nørgaard CH, Mosslemi M, Lee CJ, et al. The importance and role of multiple risk factor control in type 2 diabetes. Curr Cardiol Rep. 2019:21:35.

7. Mohammedi K, Woodward M, Marre M, et al. Comparative effects of microvascular and macrovascular disease on the risk of major outcomes in patients with type 2 diabetes. Cardiovasc Diabetol. 2017;16:95.

8. Kaul N, Ali S. Genes, genetics, and environment in type 2 diabetes: implication in personalized medicine. DNA Cell Biol. 2016;35(1):1-12.

9. Diabetes Genetics Initiative of Broad Institute of H, Mit LU, Novartis Institutes of BioMedical R, et al. Genome-wide association analysis identifies loci for type 2 diabetes and triglyceride levels. Science. 2007;316(5829):1331-6.
10. Tabatabaei-Malazy O, Khodaeian M, Bitarafan F, Larijani B, Amoli M. Polymorphisms of antioxidant genes as a target for diabetes management. Int J Mol Cell Med. 2017;6:135-47.

11. Sun P, Liu L, Chen J, et al. The polymorphism of rs 266729 in adiponectin gene and type 2 diabetes mellitus: a meta-analysis. Medicine. 2017;96(47):e8745.

12. Bengoechea-Alonso MT, Ericsson J. A phosphorylation cascade controls the degradation of active SREBP1. J Biol Chem. 2009;284:5885-95.

13. Sundqvist A, Bengoechea-Alonso MT, Ye X, Lukiyanchuk V, Jin J, Harper JW, Ericsson J. Control of lipid metabolism by phosphorylation-dependent degradation of the SREBP family of transcription factors by SCF Fbw7. Cell Metab. 2005;1:379-91.

14. Hirano $Y$, Yoshida M, Shimizu M, Sato R. Direct demonstration of rapid degradation of nuclear sterol regulatory element-binding proteins by the ubiquitin-proteasome pathway. J Biol Chem. 2001;276:36431-7.

15. Onoyama I, Suzuki A, Matsumoto A, Tomita K, Katagiri H, Oike Y, Nakayama K, Nakayama KI. Fbxw7 regulates lipid metabolism and cell fate decisions in the mouse liver. J Clin Invest. 2011;121:342-54.

16. Punga T, Bengoechea-Alonso MT, Ericsson J. Phosphorylation and ubiquitination of the transcription factor sterol regulatory element-binding protein-1 in response to DNA binding. J Biol Chem. 2006;281:25278-86.

17. Arsenault BJ, Lemieux I, Després JP, Wareham NJ, Kastelein JJ, Khaw KT, Boekholdt SM. The hypertriglyceridemic-waist phenotype and the risk of coronary artery disease: results from the EPIC-Norfolk prospective population study. CMAJ. 2010;182:1427-32.

18. Lu XY, Shi XJ, Hu A, et al. Feeding induces cholesterol biosynthesis via the mTORC1-USP20-HMGCR axis. Nature. 2020;588:479-84.

19. Nateri AS, Riera-Sans L, Da Costa C, Behrens A. The ubiquitin ligase SCFFbw7 antagonizes apoptotic JNK signaling. Science. 2004;303:1374-8

20. Vijayakumar P, Nelson RG, Hanson RL, et al. HbA1c and the prediction of type 2 diabetes in children and adults. Diabetes Care. 2017;40:16-21.

21. Welcker $M$, et al. The Fbw7 tumor suppressor regulates glycogen synthase kinase 3 phosphorylation-dependent c-Myc protein degradation. Proc Natl Acad Sci USA. 2004;101:9085-90.

22. Yeh $\mathrm{CH}$, Bellon M, Nicot C. FBXW7: a critical tumor suppressor of human cancers. Mol Cancer. 2018;17:115.

23. Koepp DM, et al. Phosphorylation-dependent ubiquitination of cyclin $E$ by the SCFFbw7 ubiquitin ligase. Science. 2001;294:173-7.

24. Jeon TI, Esquejo RM, Roqueta-Rivera M, Phelan PE, Moon YA, Govindarajan SS, Esau CC, Osborne TF. An SREBP- responsive microRNA operon contributes to a regulatory loop for intracellular lipidhomeostasis. Cell Metab. 2013;18:51-61.

25. Bengoechea-Alonso MT, Ericsson J. The ubiquitin ligase Fbxw7 controls adipocyte by targeting C/EBP alpha for degradation. Proc Natl Acad Sci U S A. 2010;107:11817-22.

26. Poznyak A, Grechko AV, Poggio P, et al. The diabetes mellitus-atherosclerosis connection: the role of lipid and glucose metabolism and chronic inflammation. Int J Mol Sci. 2020;21 (5):1835.

27. Zhao J, Xiong X, Li Y, et al. Hepatic F-box protein FBXW7 maintains glucose homeostasis through degradation of fetuin-A. Diabetes. 2018;67:818-30.

\section{Publisher's Note}

Springer Nature remains neutral with regard to jurisdictional claims in published maps and institutional affiliations. 